\title{
NARRATIVE HOUSE: A METAPHOR FOR NARRATTVE THERAPY: TRIBUTE TO MICHAEL WHITE
}

\author{
RENÉ VAN WYK \\ Department of Business Management, Faculty of Economic \\ and Management Sciences, University of Pretoria, \\ Pretoria, 0002, South Africa \\ Tel: $+124204195+832578857$ \\ Email: rene.vanwyk@up.ac.za
}

\section{Abstract}

This article is a tribute to Michael White, co-founder of narrative therapy, who passed away on 5 April 2008. Michael White and David Epston founded a substantial and groundbreaking psychological movement based on narrative therapy. Michael touched with dignity and changed for the better the lives of thousands. Michael White was an extraordinary person: philosopher, scientist and psychologist, who has opened alternative opportunities of hope to individuals through narrative therapy. Michael will be mourned by many; his teachings will be celebrated by many more. May the richness of his legacy flourish. A discussion follows concerning the theory of narrative therapy. This is illustrated by picture, depicting the main constructs of narrative therapy (figure 1), representing a metaphor of narrative therapy. This picture is in line with the therapeutic method of drawing pictures of metaphors in the counselling process, as propagated by White and Epston, and illustrated on DVD by David Epston: Narrative therapy with a young boy (Epston, 2002). The aim of the paper is not to give a linear representation of what narrative therapy should be, but rather to illustrate the main facets of narrative therapy.

\section{Introduction}

Michael White indicates that though there are specific defined stages in narrative therapy, these stages should be used creatively by therapists as a non-rigid framework (White, 2004b). White argued that every therapist should develop a distinctive personal method of narrative therapy, while keeping the principles in mind, as it should not be limited and restricted to a rhetoric science (Payne, 2006; White, 2004b). There is in other words a progression taking 
place in narrative therapy, and the principles that surface and play a role are not a linear, structured development of argument. In the counselling process, the therapist should be guided by and explore each client's unique story. White (1995a) refers to the narrative therapy process as a 'zigzagging' process between the different notions of narrative therapy.

[Please insert figure 1 here]

The aim of the discussion is to serve as a guideline and a non-stereotypical directive in which the important notions of narrative therapy play a role. The discussion is ordered in themes from the left to the right of the picture in figure 1 . The topics are not numbered, because of the non-sequential stance taken in narrative therapy. The not-knowing method of narrative therapy allows the therapist to follow the discussion by a scaffolding process (Payne, 2006; White, 2005; White \& Morgan, 2007), or an eagle flight (Botha, 2007) by observing the landscapes of identity and action in a decentred way, as storied by the client. Figure 1 serves as a guideline to direct a client from a 'problem-saturated' dominant description to a process of deconstruction and externalisation of the problem, contradicting the problem-saturated stories by means of unique outcomes, and finally re-storying alternative hopeful narratives with a richer identity, supported by a re-membering audience (Epston, 1998; White, 1991; White \& Epston, 1990).

\section{Definition of narrative therapy}

Narrative Therapy was originally developed by Michael White and David Epston during 1970-1980, referring to the way in which discourses in societies contribute to the forming of our identities (White, 2008; Wikepedia, 2008). Through narratives in therapy, people express the meaning they attach to the interpretation of their life experiences (White, 2008). During narrative therapeutic discussions, problems are objectified and metaphorically externalised as problematic and separate from the individual, so that the problem is seen as the problem and the person is not regarded as the problem (Freedman \& Coombs, 1996; Wikepedia, 2008). In this way people have the opportunity to reflect on their problematic life experiences and re-claim and re-author their lives from problem-saturated narratives into alternative richer success stories (Freedman \& Coombs, 1996; White, 2008).

\section{Modern medical model vs postmodern narrative model}

The postmodern approach of narrative therapy opposes modernistic judgments of the universal as a knowable cause and 
effect, the objectifying of observable reality, and the linguistic capturing of reality (Payne, 2006). In the modernistic medical model, the knowledge of the psychoanalyst is grounded in psychiatric expert language, with its technical terms and labels like 'schizophrenia' and 'psychopath' (Brown, Nolan, Crawford, \& Lewis (1996). This leads to a 'community of understanding' which can be compared to a 'genre' in literary studies in which certain categorisations are expected to have certain attributes according to specific norms or standards (Brown, Nolan, Crawford, \& Lewis 1996). This results in the psychoanalyst seeing patients in a clinical problematic context as sick, suffering and inferior, rather than seeing the patients' point of view, or respecting them as persons like himself. Brown, Nolan, Crawford, \& Lewis (1996) argue that for these reasons the constraints of the corporate attitude of psychiatry should be questioned and a way be made for the intelligible narratives of patients.

The argument follows that the postmodern knowledge of the narrative therapist is not trapped in the competent interpretation of the psychiatric practice, with certain background expectancies grounded on expert knowledge, but allows the re-visioning of stories of the client through the process of deconstructing the problem-saturated, thin life-story and re-construction of the alternative richer narrative (White, 1989; White, 1991; White, 2008). The weight of a narrative approach concentrates on the strength of the individual, and on mental health instead of pathology, as in the case of the medical model (Semmler \& Williams, 2000). Psychiatric illnesses would, according to the postmodern narrative approach, be a discourse that could easily limit the individual to thin descriptions, trapped in problem-saturated stories (Payne, 2006).

The narrative therapist would regard psychiatric illnesses as problems outside individuals, who have to learn to cope with these problems and create alternative landscapes of action in which they can function against the problem, not as part of the problem. Unlike the medical psychiatrist, the narrative therapist would take the stance of a nonexpert, in a not-knowing fashion, so that the client is the expert and not the therapist (Anderson \& Goolishian, 1992; Semmler \& Williams, 2000). The narrative approach would aim at deconstructing the limiting boundaries enforced by definitions of psychiatric illnesses, building a rich description that functions against the general notions of diagnosed psychiatric illnesses. The re-construction defeats problem-saturated stories that entrap individuals, re-storying them into alternative richer stories (White, 1989). 


\section{Discourses}

Hare-Mustin (1994, p. 19) defines the term discourse as 'a system of statements, practices, and institutional structures that share common values, that include both linguistic and nonlinguistic aspects; it is the medium that provides the words and ideas by means of thought and speech, as well as the cultural practices involving related concepts and behaviours'. Discourses are formed through language within social settings, leading to shared beliefs (Drewery \& Winslade, 1997; Freedman \& Coombs, 1996; White, 1989; White, 1991; Payne, 2006). It is argued that discourses are (1) socially constructed; (2) constituted through language; (3) organised and maintained through narratives; and (4) without essential truth (Freedman \& Coombs, 1996). Discourses are further referred to as expressions in language leading to conforming ways of thinking, often constructed in social groups, through shared construction of meanings (Drewery \& Winslade, 1997; White, 1991; Payne, 2006). The postmodernistic view of narrative therapy emphasises the fact that knowledge is provisionally constructed by powerful social-political influences (Payne, 2006). Therefore what is accepted as truth in one social setting is not necessarily considered as truth in another social setting.

Postmodern narrative therapy enables a person to creatively deal with the facts of the discourses that support the problemsaturated story, enabling the individual, by means of deconstruction and externalisation, to strategise an alternative plan of action against the externalised problem (Drewery \& Winslade, 1997; Epston, 1998; White, 1991; White, 2008). It acknowledges the fact that language is a metaphorical representation of reality and therefore represents only an interpretation of reality, but not reality itself. In this way the individual can claim ownership and be motivated to action against the problem, instead of being entrapped in stigmatised discourses (Epston, 1998; White, 2008). It has the potential of facilitating growth that has suffered trauma (Kaminer, 2006). This action empowers the individual to oppose discourses which are often regarded as legitimate facts of reality in spite of the fact that they are actually temporary and socio-culturally constructed (Payne, 2006).

According to Bruggeman (1993), knowledge develops from the local context in which action takes place, claimed by the dominant voices as truthful and objective. Anderson and Goolishian (1992) indicate that meaning is socially constructed through 
dialogue, and that human systems are language generated and at the same time meaning generated. The social construction of meaning through dialogue therefore leads to a local knowledge formed by dialogical exchange and a relational form of meaning (Gergen, 1992). The danger is that discourses sustain a certain world-view by means of codes and conventions. Discourses categorise the social world, making certain phenomena important, while obscuring other phenomena. The formation of discourses is at the heart of the construction of meaning. Most people in society sustain discourses through shared viewpoints. The potential danger of the formation of discourses is that they are taken for granted, unable to be questioned, forming part of the identity of members of society, and similarly influencing the attitudes and behaviours of those members.

\section{The problem is the problem; the person is not the problem}

From the investigation of discourses follows the idea initiated by White (1989) of the problem being the problem and not the person being the problem (Epston, 1998; Freedman \& Coombs, 1996). Persons who experience themselves as the problem feel helpless and experience a loss of personal agency about manoeuvring themselves away from the problem, unable to initiate self-change. When the problem is identified as the problem (the antagonist), the person is empowered, as protagonist, to take the lead in creatively taking control of the problem (Semmler \& Williams, 2000). In narrative therapy the problem is set up as antagonist and the person is promoted to protagonist in the story, with the client and counsellor in partnership co-authoring empowering and meaningful alternative stories, the reverse of the narratives of failure (Semmler \& Williams, 2000; Winslade, Crocket, \& Monk, 1997).

It is more important in narrative therapy to focus on the content of restraints that keep the problem alive than investigate the origin or pathology of the problem (Durrant \& Kowalski, 1998). Deconstruction of the problem needs to take place through externalisation, by describing and distinguishing the problem as an entity outside the person (Durrant $\&$ Kowalski, 1998). This kind of argument enables a person to view the problem as separate and external to the individual functioning on the outside. The problem can then be faced objectively, rather than being viewed as a part of the person. It can be considered as if it is a distinct entity that is somehow affecting and dominating the person from outside. The person is seen as facing a problem, rather than having a problem. 
This stance enables the individual to entertain ideas that he or she has some agency over the problem.

\section{How does a dominant story develop?}

According to Freeman, Epston, \& Lobovits (1997), dominant stories are formed from the memories and experiences of individuals through views of family members and significant other individuals co-validating a dominant story of a person's life. Dominant stories tend to prevent the infiltration of alternative experiences, hope and capabilities, and so lead to self-fulfilling assumptions. It is the aim of the narrative therapist to liberate and empower individuals to break free from the dominant problem-saturated story and separate their individuality and identity from the problem.

\section{Deconstruction}

Foucault warns that one should be sensitive to claims of truths in modern science that try to objectify, and in the process dehumanise, people (Freedman \& Coombs, 1996; Monk, 1997). At the root of narrative therapy is the belief that human problems and dilemmas could consist of unhealthy discourses which are manufactured in a social context, rather than innate to the individual (Semmler \& Williams, 2000). A discourse of an individual which has been formed within a given culture by outdated, inappropriate views, with their laden values and biases, needs to be deconstructed (Freedman \& Coombs, 1996). These might include the image the media create that women should be slim to be attractive, or the idea that people should be erotically in love to be happy.

Deconstruction takes place by inviting a person to engage in the questioning of seemingly social truths (Payne, 2006; White, 1991; White, 1996; White \& Epston, 1990). An individual is encouraged to investigate the possible influences of unrecognised societal beliefs and notions that have contributed to the construction of a discourse. The ascribed meanings of these discourses are investigated with the option of redefining the meaning of events. In this way individuals are invited to externalise problems as separate from their character and individual traits, and consider the socio-cultural-political contribution to the forming of characteristic discourses as external to themselves.

The deconstruction of discourses sensitises the individual to the possible deceptiveness and ambiguousness of language, as it is temporally and socially constructed and should not be given a literal interpretation that is restrictive, limiting and damaging to a person's self-definition (Payne, 2006; White, 1991). The postmodern re-storying 
of problem-saturated plots is in line with the anthropological rejection of the therapist as having expert knowledge (Payne, 2006). In place of the modern objective expert's knowledge, postmodern interaction encourages subjective personal interpretation of experiences, with the therapist engaging in not-knowing discussions, with the client as the expert (White, 1991). People are respectfully encouraged to engage in the creative ways in which they ingeniously restructure their own lives into realistic self-empowered alternative stories (Morgan, 2000; Payne, 2006). Monk (1997) metaphorically refers to the preferred alternative story as building a fire and constantly feeding it with new possibilities.

The challenge in identifying a discourse is to dismantle the power relations formed by pathological discourses or societal misconceptions. A discourse formed by storying is not necessarily destructive to the individual, in fact could also promote competence and wellness, but negative stories or discourses could restrict and even pathologise behaviour. Deconstruction takes place in three stages, by (1) separating the person from the problem and historically dominant negative perceptions; (2) sensitising the individual to alternative, optimistic and constructive possibilities; and (3) the reincorporation of the discovery of legitimate indiosyncratic authenticism, validated by meaningful other individuals (Payne, 2006).

\section{Externalisation and metaphor}

Externalising a problem is a distinctive narrative therapy characteristic, developed by Michael White (Monk, 1997). Externalisation enables an individual to objectify and personify an oppressive problem (White, 1989). It positions the person as separate from the problem, with the problem interpreted as external rather than internal, empowering the individual to become a creative agent in problem solving, rather than a passive patient (Monk, 1997; White, 1989; White, 1991). Externalising implies giving the problem a metaphorical name - this naming is negotiated between the therapist and the client (Morgan, 2000; Payne, 2006, p. 58). This emphasises the fact that the problem is not a fixed, inherent characteristic of the individual. Externalisation facilitates the evaluation of problems metaphorically, as less permanent and constraining and more flexible. Externalisation liberates a person to approach a seemingly intimidating, rigid, unchangeable problem by objectifying it, therefore empowering the individual to manage it purposefully (Payne, 2006). Through externalisation the individual is invited to verbally reflect upon an extrinsic problem, and to use the power of metaphorical 
language to counter the images and beliefs that the problem is inherent to the person's identity (Payne, 2006). A more relaxed, less threatening atmosphere is introduced (White, 1991, White, 1995a; White 1995b).

Payne (2006) warns that externalising is not effective if it is not used post-structurally. It should therefore enable the person to break away from observing the problem as an internal fixed or pathological characteristic. Through externalisation the problem should be deconstructed, by making a thorough, detailed, meticulous and exhaustive evaluation of the beliefs and assumptions that maintain the problem, referred to as the landscape of identity.

It is important to notice that externalisation and the use of metaphor is not limited to problems. It can similarly be used to name positive newly developed narratives for individuals (Payne, 2006). Externalisation also lends authority to the individual to reconstruct strengths and positive characteristics in forming a new identity (Carey \& Russel, 2002).

\section{Thin versus thick descriptions}

Freemar, Epston, \& Lobovits (1997) indicate that individuals' dominant stories are formed through co-validation by significant other persons of the individual's dominating story of his or her life. These dominant stories, by thinning and narrowing the character of the individual, could prevent him or her from acknowledging alternative experiences in which the dominant story does not feature. Problems tend to lead to a thin description, saturated with narratives that support the problem, and possibly in addition 'expert' analyses and diagnoses (White, 1991; White \& Epston, 1990). It is often the powerful opinions of expert figures and institutions that limit the description of an individual to thin, lean characteristics (Payne, 2006). Through deconstruction and externalisation a person may realise that selfworth is not dependent on the opinions of individuals that prescribe, support and sustain the problem (Payne, 2006).

Deconstruction and externalisation allow an individual to resist the truth status of thin descriptions of socially constructed problems (Payne, 2006), which reject the notion of having a 'core self'. Thin descriptions of behaviour tend to lead to problem-saturated narratives in which persons view themselves in the world through the lens of the defined problem of the self (Durrant $\&$ Kowlaski, 1998). Rejecting thin descriptions of problem-saturated stories makes it possible to renegotiate the problem as not being part of the person (Gergen \& Davis, 1985; Anderson 1997; Gergen, 1992, 1999). The ideal is that the client develops a broader and thicker solution-orientated view of 
the self, in which the lens of achievement of solutions replaces the thin problem lens through which life is viewed. In this way a new lens of competence and self-respect is formed, replacing the notions of incompetence, self-hate and self-blame. The ideal is to explore contradictions of the thin story and to utilise these exceptions to build a new, competent self-view.

A thin description of an individual does not acknowledge the full personal characteristics and potential of the individual. Morgan (2000) points out that the narrative therapist is initially overwhelmed with thin descriptions of problem-saturated stories, which are sten as common truths. The ideal is to form, through deconstruction, externalisation and utilisation of descriptive metaphor, altemative thick descriptions of the individual. These alternative narratives do not support or sustain the limitations of thin descriptions of the problem-saturated story, but create new possibilities of living. In order to thicken the alternative story, it is helpful to find witnesses who can act as supportive members in the strengthened new story (Morgan, 2000).

\section{Unique outcome}

A unique outcome is a sparkling moment, a situation in which the problem does not feature, indicating the self-efficacy of the individual in creating solutions and not being intimidated by the problem (Durrant \& Kowalski, 1998; Monk, 1997). It provides an individual with clear-cut historical evidence that things can be different, that the problem does not always dominate. When the therapist explores the client's relationship with the problem, the possibility of unique outcomes is enhanced, enabling the therapist to alert the client to exceptions to the dorinant story that often go unnoticed (Epston, 1998; Freeman, Epston, \& Lobovits, 1997; White \& Epston, 1990). Durrant and Kowalski (1998) refer to urique outcomes as the discovering of exceptions, exploring with the client occasions when the problem was not a problem, or less of a problem. By searching for unique outcomes and refraining from using pathological language, a richness of ideas can be discovered that honours the resilience of an individual, notwithstanding exposure to adversity (Ungar, 2005). This paves the way for the client to break out of the entrapment of the dominant story, liberating him or her to create alternative preferred stories and follow a solution-focused approach.

In order to identify a unique outcome, the therapist should sustain alertness to any description of an experience that contradicts the cynical dominant problem story, leading to the self-efficacy of a 
likely alternative perspective (Payne, 2006). It is through exploring the history of exceptional outcomes that alternative stories are rendered, and the roots of these possibilities nurtured into alternative narratives of success and finally successful behavioural actions (White, 1995; White \& Epston, 1990). The therapist must be sensitive to identifying such clues when exploring sub-plots in the narratives of individuals (Payne, 2006).

Niehaus (2003) relates that she asked a story teller to give a thicker description of a unique outcome. This was celebrated by means of a ritual. According to Niehaus (2003) this is a significant step in separating the client from the problem-saturated story and moving to a preferred life version. Rituals are celebrations of a person's victory in taking charge of the problem, authenticating the identity of the individual doing so (Epston, 1998). This enables the protagonist to reject a previous problem-saturated relationship, empowering the re-authoring of thicker descriptions of resilient behaviour. Ungar (2005) also acknowledges the role that the community serves in helping a client to develop resilient behaviour. In this way previous painful voices are challenged, at first by means of uncertain backchatting, followed by more spontaneous, confident control and rejection of the problem (Niehaus, 2003).

White (1989, p. 38) cautions that the identification of unique outcomes does not simply imply 'pointing out positives'. It is rather a discovery of inherent hidden strengths (Payne, 2006; White, 1989). Simply pointing out positives does not invite the client to use the uniqueness of a positive outcome as a building block to a solution-oriented approach. The danger is that positive statements of resilience could lend themselves to more thin descriptions, by simply applauding the client's behaviour, in place of thickening the description of resilience as it is lived by the individual (Ungar, 2005). Positives should not just be pointed out, but should be explored (Durrant \& Kowalski, 1998). The client must be invited to be as specific as possible when experiencing exceptions and describing them in detail, with questions such as: "Tell me more about what you did differently when you managed to stand up against the problem'; What did it feel like?'; 'What does it say about you as a person?' Resilient thickening of unique outcomes supports a salutogenic health-seeking discourse of personal well-being (Ungar, 2005).

The identification of discourses, metaphorically externalising the problem and identifying unique outcomes, activates a process of continual deconstruction. Deconstruction allows the client to resist negatives of social conditioning and reclaim alternative ways of being 
(Wylie, 1994). Deconstruction opens the prospect for people to narrate incidents in their lives that have not yet been storied through the landscape of identity (Freedman $\&$ Coombs, 1996). In order to improve deconstruction, and re-storying of unique outcomes:

- The deconstructionist should search for gaps and ambiguities in the officially sanctioned, generally accepted meanirigs of discourses.

- In thickening the stories of unique outcomes, individuals are encouraged to identify ambiguities in the problem-saturated story by being asked to resolve or deal with those ambiguities.

- Individuals are also encouraged to fill gaps in narratives by restorying and shaping narrative changes in detail.

- Individuals should experience the narration of their unique outcomes as something they had control in shaping and not just something that shaped them.

- Deconstruction, and thickening of the possibilities unique outcomes envisage, loosens the grip of restrictive discourses.

Deconstructive listening and the identification of unique outcomes follow from attentively 'not-knowing', exploring the landscape of action through scaffolding and an eagle flight - an ability to perceive the individual as separate from problems, broadening the landscape of action in order to join forces to oppose the problem and its effects (Botha, 2007; Durrant \& Kowalski, 1998; Freedman \& Coombs, 1996). Scaffolding and an eagle's flight represent the functioning of the therapist on the level of the individual's experiences - putting herself in the shoes of anc observing the narrative of the person (Botha, 2007; Mork, Winslade, Crocket, \& Epston, 1997). When a certain clegree of trust nd mutual understanding has been achieved, the therapist should shift ion deconstructive listening to deconstructive questionir 3 , inviting individuals to see their stories from alternative perspectives, perceive the boundaries of discourses, and open up the possibilities of other narratives, realising that discourses are not inevitable and uncontrollable (Botha, 2007; Monk, Winslade, Crocket, \& Epston 1997; Freedman \& Coombs, 1996).

As soon as this has been established, the door is opened for individuals to commit themselves to dis-approving the restrictions of historical discourses. Deconstructive questioning enables the individual to reclaim other aspects and experiences that are also part of the self but not part of the problem. Freedman \& Coombs (1996) point out that deconstructive questions can help individuals to unpack stories and distinguish themselves from particular beliefs, practices, feelings, and attitudes. This encourages them to see 
themselves through their narratives in a larger system and broaden their scope, allowing more 'sparkling' events to come forth.

Exploring unique outcomes invites and repositions an individual to narrate richer life experiences and explore situations in which the problem is under control. This allows the individual to advance from the narrative of being dominated by the problem to mapping authority over the problem (White, 1989). The ideal is to adopt a stance of curiosity, inviting clients to entertain the idea of personal agency, because clients sometimes tend to persistently fall back into viewing the problem through the 'problem-saturated' lens (Durrant \& Kowalski, 1998).

\section{The relationship between unique outcomes and alternative stories}

Threading together unique outcomes offers the individual story teller the opportunity to create and name an alternative story (Semmler \& Williams, 2000; White \& Epston, 1990). It provides the building blocks for a re-authored story. It allows individuals to shape their own values, rather than being limited by those that the problem prescribes (Freeman, Epston, \& Lobovits, 1997; White \& Epston, 1990). Unique outcomes serve as the raw material for building new self-descriptions forming alternative stories, a new competent self (Durrant \& Kowalski, 1998). Alternative stories empower the client to exercise control over previously overwhelming feelings or behaviours.

According to Morgan $(2000$, p. 72 ) the naming of the alternative story brings about the following advantages:

- The process helps the individual to further separate herself from the dominant story, allowing space for alternative considerations.

- The personal preferences become more obvious, making it easier for the individual to act out choices.

- Naming both the dominant and alternative stories provides a framework for the individual to map and plan future events.

- These names serve as a point of reference for future conversations between client and therapist.

- By the client's naming the alternative story the therapist is enabled to enquire and explore the alternative story and ask about choices and preferences.

- The naming of the alternative story allows space for the development of rich descriptions and explorations around it. 


\section{Landscape of action vs landscape of identity and consciousness}

While Freedman and Coombs (1996) refer to the landscapes of action and consciousness, Morgan (2000, p. 60) and White (1989, 1991, 2004a; 2004b) similarly refer to the landscapes of action and identity'. These authors indicate that therapists should enquire about both these landscapes, as stories of individual's lives develop simultaneously in both these landscapes. Michael White prefers the term landscape of identity' to the Freedman and Coombs (1996) term 'landscape of consciousness', as he argues that it is the identity of the person that is affected through the therapeutic process (White 2004a; White 2004b). It is the interplay between these dual landscapes of identity/consciousness and action that encourages experiential and empathic involvement with the story character (Freedman \& Coombs, 1996; Morgan, 2000; White 2004a; White 2004b).

Meaning questions should be initialised to explore the landscape of identity/consciousness, which gives the story teller the opportunity to reflect on the wishes and competencies in the landscape of action (Freedman \& Coombs, 1996). There should be a backwards and forwards weaving or zigzagging of enquiries between these dual landscapes of consciousness/identity and action (Freedman \& Coombs, 1996; White 2004a; White 2004b). In order to explore and reflect on the meaning and preferred outcomes of alternative future landscapes of action and identity, both landscapes should be explored (Morgan, 2000). Landscape of action is the opening up of a story in discussion with the client, explained as the who, what, when, where, and how' - in other words, the agent, intention/ goal, and situation (Freedman \& Coombs, 1996). Enquiries into the landscape of action explore viewpoints and modalities of multiple characters in particular scenes and settings. Morgan (2000) indicates that enquiries into the landscape of action not only inquire about particulars of a specific outcome, but also events and actions that may be linked to it.

White (1991) indicates that questions on the landscape of identity assist individuals in developing a new alternative landscape of action, revealing:

- the nature of their preferences or desires

- the character of relationship qualities

- detail concerning their intentional states

- exploration of new-found beliefs, and

- the nature of their intended commitments. 


\section{The role of the not-yet-said in narrative therapy and its relationship with unique outcomes}

Semmler \& Williams (2000) indicate that it is the role of the therapist to guide and uncover overlooked possibilities of client's experiences that are not part of the problem-saturated story. Exploring the history of a problem opens possibilities of finding other alternative stories about the problem, those not-yet-said (Morgan, 2000). This is a search for anti-problem stories that brings forth people's skills, abilities, competencies and commitments' that are not part of the problem (Morgan, 2000, p. 59).

Anderson \& Goolishian (1992) emphasise the not-knowing approach in narrative therapy, which the therapist should follow in order to find the not-yet-said. The therapist is thus led by the client. This not-knowing perspective allows the unforeseen to become part of the realm of possibilities. This is the development of the not-yetsaid, unrealised possibilities allowing a different understanding of the problem. Not-yet-said narratives, as new agency and meaning, can bring about change in the individual. Not-knowing allows interpretive change to take place as a point of departure towards forming not-yet-said new stories. The development of the not-yetsaid is formed by the therapist's curiosity and not-knowing and willingness to learn, which opens and liberates conversational space, allowing the narrative development of new agency and personal freedom.

According to White (1989), re-storying that takes place through investigating and exploring the implicit strengths of the individual that were never-thought-of should be discussed as a pattern with speculative new prospects. Through re-membering, significant other individuals, important to the celebration of and belief in the re-storying of the client, should be invited into the discussion of forming new meanings. Re-membering can also include re-connecting with loved ones who have passed away, whom the client has cherished (Monk, 1997; Nasim, 2007). Re-membering of significant individuals will contribute to the empowered re-storying and re-authoring of the client's future expectancies of standing up against the previous problem-saturated story. Re-membering can include the comfort and support found in memories of people, even strangers, who have significantly and positively contributed to the individual's life, by 'inviting' such individuals to metaphorically form a membership in rejoicing over the reclaimed alternative story of the client (Payne 2006). Therapy will be terminated when the client's alternative story is rich enough to affirm and sustain the living of the alternative narrative. 


\section{Contradicting the problem}

Externalising the problem is an indication to individuals that their problems are separate from themselves (Epston, 1994; Epston, 1998; Morgan, 2000). Externalisation authorises the story-teller to manoeuvre and separate his or her identity from the problem, allowing the reflection on unique outcomes to serve as gateway to the preferred alternative story (Barry, 1997, Freeman, Epston, \& Lobovits, 1997). It also allows the individual to become free at an individual level and break out of the mould of internalised oppressive ideas, habits and practices, so that a new self-definition takes place (O'Hanlon, 1994). Externalisation, does not, however, destroy or annihilate problems; it rather empowers the individual to activate preferred relationships with the problem, as it is not the problem that is the problem, but the individual's relationship with the problem that needs to be addressed (Epston, 1998).

Externalisation separates the client from the problem and encourages him or her to take charge of oppressive problems and recreate a reality through new dominant stories (Merscham, 2000). Externalisation is enhanced by recruiting an audience who would witness the new story and thus solidify it. For instance, the client could be asked: Who would first notice that you have banished 'depression?' (Durrant \& Kowalski, p. 88). Unique outcomes then serve as a platform of exceptions on which to build, assisting a person in identifying with solutions. Both externalisation and the identification of unique outcomes authorise the clients to see themselves and others from a non-problem-saturated perspective. Identifying unique outcomes and externalising problems by means of metaphor often serves as a great relief to a client, offering space for the disempowerment of fixed and restricting ideas that impoverish people's lives (Morgan, 2000). This allows for the development of an alternative story, and the exploration of unique outcomes and re-storying of the future competencies.

\section{The role of letter writing in narrative therapy}

Epston (1998) indicates that for him, letter writing has a long association with narrative therapy, and that the majority of his clients receive a letter after each meeting. As opposed to conversations that tend to be ephemeral, with clients often walking out of a consultation session trying to remember the exact words of the discussion, letters bear witness to therapy. David Epston (1998) says that some of his clients reread the letters he has sent them, even years after therapy, to remind 
themselves of the advances they have made by externalising the problem and intervening in their own lives. Epston sees letter writing as intertwined with therapy, in order to make therapy transparent to the client. White and Epston (1990) regard the procedure of letter writing as reporting on the constructive information gathered in a session as well as adding questions and reflections on the session.

\section{Invitations from the future}

Epston, Lakusta, \& Tomm (2006, p. 65) introduce the concept of 'haunting from the future by friendly ghosts', through which the clicint is invited to evaluate his current state by imagining looking back at the current circumstances in 15 or 20 years. Free rein should be given to these friendly future haunts, in which the client is allowed to respond to a future reaction to the best version of a current conviction (Epston, Lakusta, \& Tomm, 2006). A friendly ghost is fictionally invited from the future to haunt the client in the present, inviting the client to imagine dealing resourcefully with the present. Similarly a client can be invited to develop a ritual of celebration of a future festival in commemorating the future success story.

Invitations from the future are similar to the concept of inviting imaginary friends to solve problems (Betterton \& Epston, 1998). A ten-year old girl disclosed to David Epston how she invited an imaginary friend to assist her in resisting her habit of nocturnal thumb-sucking, loneliness, doing homework and even making real friends. The advantage of these imaginary friends is that they are always supportive, and always treat you well. Epston (1998) calls this ability of having imaginary friends the advantage of being weirdly able.

\section{Conclusion}

Self-realisation is developed through narrative therapy by promoting the client's autonomy and empowerment. Deconstruction through narrative therapy challenges the view of an individual as having a fixed personality by taking a stance against powerful discourses created by society. This happens by collaboratively examining the restrictions placed by such discourses. The naming of the alternative story enables the client to counter-plot, articulate its effect and thicken the alternative story. This enables a linkage to a newly formed landscape of action. 


\section{References}

Anderson, H. (1997): Conversations, language, and possibilities: A postmodern approach to therapy. New York: BasicBooks.

Anderson, H., \& Foley, E. (1998): Mighty stories, dangerous rituals. Weaving together the human and the hivine. San Francisco: Jossey-Bass.

Anderson, H., \& Goolishian, H. (1992): The client is the expert: A not-knowing approach to therapy. In S. McNamee \& K.J. Gergen (Eds.), Therapy as Social Construction (pg. 25-09). London: Sage.

Barry, D. (1997): Telling changes: From narrative family therapy to organizational change and development. Journal of Organizational Change Management, Vol.10, and No.1. pg. $30-46$.

Betterton, E., \& Epston, D. (1998): Imaginary friends: Who are they? Who needs them? In D. Epston (Ed.), 'Catching up' with David Epston: A collection of narrative practice-based papers published between 1991 \& 1996 (pg. 69-72). Adelaide: Dulwich Centre Publications.

Botha, A. (2007): Verbal communication with the author on 5 June. Pretoria (Casette recording in possession of author).

Brown, B., Nolan, P., Crawford, P., \& Lewis, A. (1996): Interaction, language and the 'narrative turn' in psychotherapy and psychiatry. Social Science Medicine, Vol.43, and No.11. 15691578.

Bruggeman, W. (1993): Texts under negotiation: Bible \& Postmodern Imagination. London: SCM Press.

Carey, M. \& Russell, S. (2002): Externalising: commonly asked questions. International Journal of Narrative Therapy and Community Work, Vol.2, pg. 76-84.

Drewery, W., \& Winslade, J. (1997): The theoretical story of narrative therapy. In G. Monk, J. Winslade, K. Crocket, \& D. Epston (Eds.), Narrative therapy in practice: The archaeology of hope (pg. 32-52). San Francisco, CA: Wiley.

Durrant, M., \& Kowalski, K. (1998): Overcoming the effects of sexual abuse: self-developing a self-perception of competence. In M. Durrant, \& C. White (Eds.), Ideas for therapy with sexual abuse (pg. 65-110). Adelaide: Dulwich Centre Publications.

Epston, D. (Ed.). (1998): 'Catching up' with David Epston: A collection of narrative practice-based papers published between 1991 \& 1996. Adelaide: Dulwich Centre Publications.

Epston, D. (2002): Narrative therapy with a young boy: An interview with David Epston. RC489 .S74 N37. Retrieved 
April 28, 2008 from http://osulibrary.oregonstate.edu/ video/med40.html.

Epston, D., Lakusta, C., \& Tomm, K. 2006. Haunting from the future: A congenial approach to parent-children conflicts. The International Journal of Narrative Therapy and Community Work, Vol.2, pg. 61-70.

Freedman, J., \& Coombs, G. (1996): Narrative therapy: The social construction of preferred realities. New York: Norton.

Freeman, J., Epston, D., \& Lobovits, D. (1997): Playful approaches to serious problems: Narrative therapy with children and their families. London: Norton.

Gergen, K. (1992):Towards a postmodern psychology, In S. Kvale (Ed.). Psychology and Postmodernism (pg. 17-30). London:Sage.

Gergen, K. (1999): An introduction to social construction. London: Sage.

Gergen, K., \& Davis, K. (Eds.) (1985): The social construction of the person. New York: Springer.

Hare-Mustin, R.T. (1994): Discourses in the mirrored room: A postmodern analysis of therapy. Family Process, Vol.33. pg. 19-35.

Kaminer, D. (2006): Healing processes in trauma narratives: A review. South African Journal of Psychology, Vol.36, and No.3. pg. 481-499.

Merscham, C. (2000): Restorying trauma with narrative therapy: Using the phantom family. The Family Journal: Counseling and Therapy for Couples and Families, Vol.8, and No. 3. pg. 282-286.

Monk, G. (1997): How narrative therapy works. In G. Monk, J. Winslade, K. Crocket, \& D. Epston (Eds.) (pg. 3-31). Narrative therapy in practice: The archaeology of hope. San Francisco, CA: Wiley.

Monk, G., Winslade, J., Crocket, K., \& Epston, D. (Eds.). (1997): Narrative therapy in practice: The archaeology of hope. San Francisco, CA: Wiley.

Morgan, A. (2000): What is narrative therapy? An easy-to-read introduction. Adelaide: Dulwich Centre Publications.

Nasim, R. (2007): 'A different story': Narrative group therapy in a psychiatric day centre. The International Journal of Narrative Therapy and Community Work, Vol.1. pg. 15-28.

Niehaus, E. (2003): Narratives of relationships/marriages. Unpublished Master's thesis. Pretoria: University of South Africa. 
O'Hanlon, B. (1994): The third wave. Family Therapy Networker, Vol.18. pg. 19-29.

Payne, M. (2006): Narrative therapy. An introduction for counsellors. 2nd ed. London: Sage.

Semmler, P. L., 8, Williams, C. B. (2000): Narrative therapy: a storied context for multicultural counselling. Joumal of Multicultural Counseling \& Development, Vol.28, and No.1. pg. 51-61.

Ungar, M. (2005): A thicker description of resilience. The International Joumal of Narrative Therapy and Community Work, Vol.3\&4. pg. 89-96.

White, M. (1989): Selected Papers. Adelaide: Dulwich Centre Publications.

White, M. (1991): Deconstruction and therapy. Dulwich Centre Newsletter, Vol.3. pg. 21-40.

White, M. (1995a): Re-authoring lives: Interviews and Essays. Adelaide: Dulwich Centre Publications.

White, M. (1995b): Externalizing Conversations Exercise. Adelaide: Dulwich Centre Publications.

White, M. (2004a): Narrative Practice and Exotic Lives. Adelaide: Dulwich Centre Publications.

White, M. (2004b): Working with people who are suffering the consequences of multiple trauma. International Journal of Narrative Therapy and Community Work, Vol.1. pg. 45-76.

White, M. (2005): Workshop Notes. Retrieved April 28, 2008 from http://64.233.183.104 search?q=cache:9Vtb0uXhmyIJ: dulwichcentre.com.au/Michael\%2520White\%2520Work shop $\% 2520$ Notes.pdf + michael+white+scaffolding $\&$ hl $=e n$ \&ct $=\mathrm{clnk} \& \mathrm{~cd}=1 \& \mathrm{gl}=\mathrm{za}$

White, M. (2008): Narrative Therapy. Retrieved April 28, 2008 from http://www.massey. ac.nz/ /virtual/white.htm.

White, M., \& Epston, D. (1990): Narrative means to therapeutic ends. New York: Norton.

White, M., \& Morgan, A. (2007): Narrative therapy with children and their families. Adelaide: Dulwich Centre.

Wikepedia. (2008): Narrative therapy: Wikipedia free encyclopedia. Retrieved April 28, 2008 from http://en.wikipedia.org/wiki/ Narrative therapy.

Winslade, J., Crocket, K., \& Monk, G. (1997): The therapeutic relationship. In G. Monk, J. Winslade, K. Crocket, \& D. Epston. (Eds.), Narrative therapy in practice: The archaeology of hope (pg. 53-81). San Francisco, CA: Wiley.

Wylie, K. (1994): Panning for gold. Family Therapy Networker, Vol.18. pg. 40-48. 
Narrative therapy metaphor: house

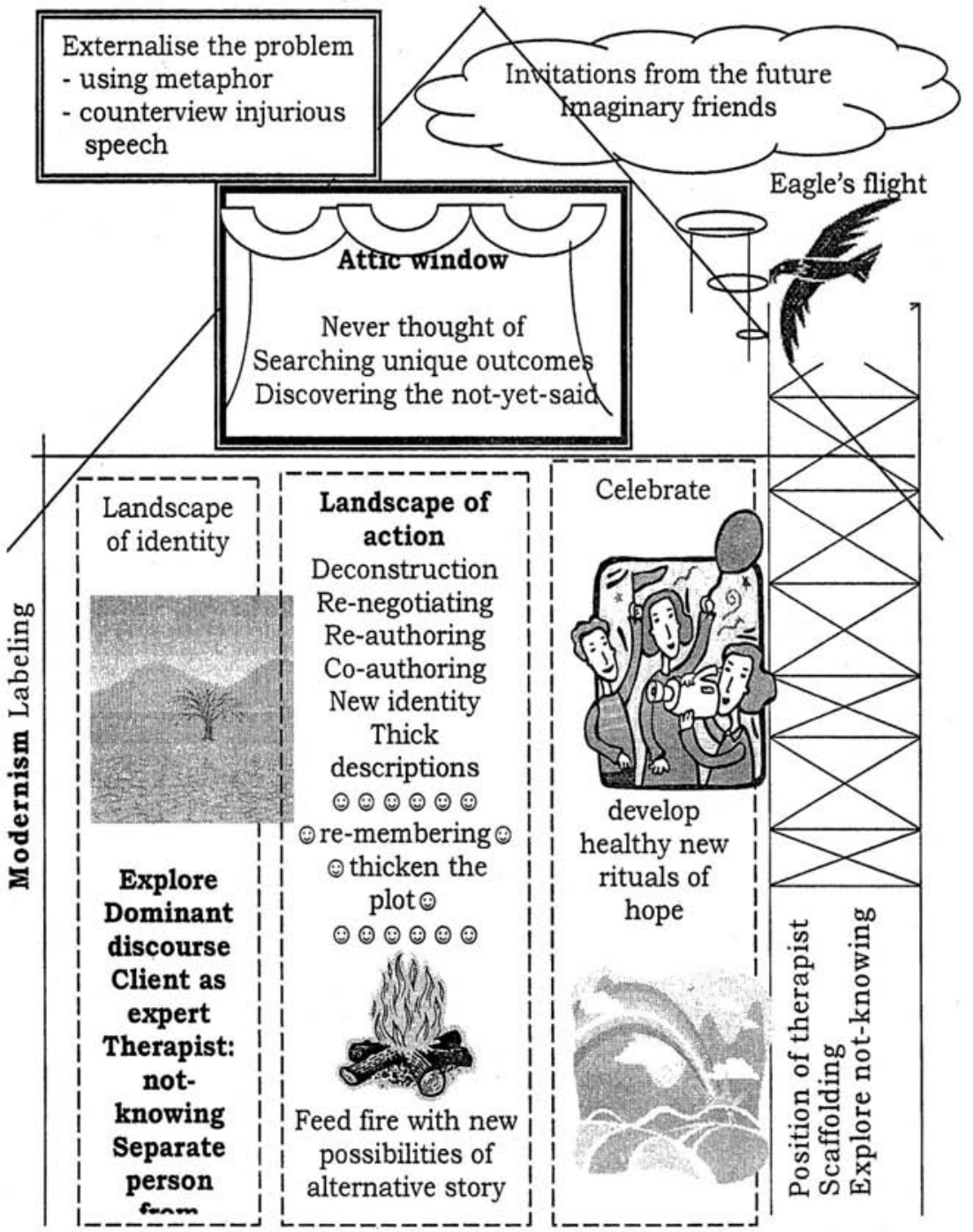

Foundation Postmodern: The problem is the problem, the person is not the problem

Figure 1. Narrative therapy metaphor: house 